\title{
Diagnosing deep vein thrombosis in cancer patients with suspected symptoms: An individual participant data meta-analysis
}

Citation for published version (APA):

Takada, T., van Doorn, S., Parpia, S., de Wit, K., Anderson, D. R., Stevens, S. M., Woller, S. C., ten CateHoek, A. J., Elf, J. L., Kraaijenhagen, R. A., Schutgens, R. E. G., Wells, P. S., Kearon, C., Moons, K. G. M., \& Geersing, G. J. (2020). Diagnosing deep vein thrombosis in cancer patients with suspected symptoms: An individual participant data meta-analysis. Journal of Thrombosis and Haemostasis, 18(9), 2245-2252. https://doi.org/10.1111/jth.14900

Document status and date:

Published: 01/09/2020

DOI:

10.1111/jth.14900

Document Version:

Publisher's PDF, also known as Version of record

Document license:

Taverne

Please check the document version of this publication:

- A submitted manuscript is the version of the article upon submission and before peer-review. There can be important differences between the submitted version and the official published version of record.

People interested in the research are advised to contact the author for the final version of the publication, or visit the DOI to the publisher's website.

- The final author version and the galley proof are versions of the publication after peer review.

- The final published version features the final layout of the paper including the volume, issue and page numbers.

Link to publication

\footnotetext{
General rights rights.

- You may freely distribute the URL identifying the publication in the public portal. please follow below link for the End User Agreement:

www.umlib.nl/taverne-license

Take down policy

If you believe that this document breaches copyright please contact us at:

repository@maastrichtuniversity.nl

providing details and we will investigate your claim.
}

Copyright and moral rights for the publications made accessible in the public portal are retained by the authors and/or other copyright owners and it is a condition of accessing publications that users recognise and abide by the legal requirements associated with these

- Users may download and print one copy of any publication from the public portal for the purpose of private study or research.

- You may not further distribute the material or use it for any profit-making activity or commercial gain

If the publication is distributed under the terms of Article $25 \mathrm{fa}$ of the Dutch Copyright Act, indicated by the "Taverne" license above, 


\title{
Diagnosing deep vein thrombosis in cancer patients with suspected symptoms: An individual participant data meta- analysis
}

\author{
Toshihiko Takada $^{1}$ | Sander van Doorn ${ }^{1}$ | Sameer Parpia ${ }^{2}$ | Kerstin de Wit ${ }^{3}$ | David \\ R. Anderson ${ }^{4}$ | Scott M.Stevens ${ }^{5,6}$ | Scott C. Woller, ${ }^{5,6}$ | Arina J.ten Cate-Hoek ${ }^{7}$ | \\ Johan L. Elf ${ }^{8}$ | Roderik A. Kraaijenhagen ${ }^{9}$ | Roger E. G. Schutgens ${ }^{10}$ | Phil S. Wells ${ }^{11}$ | \\ Clive Kearon $^{3}$ | Karel G. M. Moons ${ }^{1}$ | Geert-Jan Geersing ${ }^{1}$ \\ ${ }^{1}$ Julius Center for Health Sciences and Primary Care, University Medical Center Utrecht, Utrecht University, Utrecht, The Netherlands \\ ${ }^{2}$ Department of Oncology, McMaster University, Hamilton, Canada \\ ${ }^{3}$ Department of Medicine, McMaster University, Hamilton, Canada \\ ${ }^{4}$ Division of Haematology, Department of Medicine, Dalhousie University, Halifax, Canada \\ ${ }^{5}$ Department of Medicine, Intermountain Medical Center, Murray, UT, USA \\ ${ }^{6}$ Department of Internal Medicine, University of Utah School of Medicine, Salt Lake City, UT, USA \\ ${ }^{7}$ Department of Internal Medicine, Maastricht University Medical Center, Maastricht, The Netherlands \\ ${ }^{8}$ Vascular Center, Skane University Hospital, Malmö, Sweden \\ ${ }^{9}$ Department of Medicine, Academic Medical Center, Amsterdam, The Netherlands \\ ${ }^{10}$ Van Creveld Clinic, University Medical Center Utrecht, Utrecht University, Utrecht, The Netherlands \\ ${ }^{11}$ Department of Medicine, Ottawa Hospital, University of Ottawa, Ottawa, Canada
}

\section{Correspondence}

Geert-Jan Geersing, Julius Center for Health Sciences and Primary Care, University Medical Center Utrecht, Utrecht University, Universiteitsweg 100, 3584 CG Utrecht, The Netherlands.

Email: G.J.Geersing@umcutrecht.nl

\begin{abstract}
Background: A previous individual participant data (IPD) meta-analysis showed that the Wells rule and D-dimer testing cannot exclude suspected deep vein thrombosis (DVT) in cancer patients.

Objectives: To explore reasons for this reduced diagnostic accuracy and to optimize the diagnostic pathway for cancer patients suspected of DVT.

Patients and Methods: Using IPD from 13 studies in patients with suspected DVT, DVT prevalence and the predictive value of the Wells rule items and D-dimer testing were compared between patients with and without cancer. Next, we developed a prediction model with five variables selected from all available diagnostic predictors. Results: Among the 10002 suspected DVT patients, there were 834 patients with cancer. The median prevalence of DVT in these patients with cancer was $37.5 \%$ (interquartile range [IQR], 30.8-45.5), whereas it was 15.1\% (IQR, 11.5-16.7) in patients without cancer. Diagnostic performance of individual Wells rule items and D-dimer
\end{abstract}


testing was similar across patients with and without cancer, except "immobility" and "history of DVT." The newly developed rule showed a pooled c-statistic 0.80 (95\% confidence interval [Cl], 0.75-0.83) and good calibration. However, using this model, still only $4.3 \%(95 \% \mathrm{Cl}, 3.0-5.7)$ of the suspected patients with cancer could be identified with a predicted DVT posttest probability of $<2 \%$.

Conclusions: Likely because of the high prevalence of DVT, clinical models followed by D-dimer testing fail to rule out DVT efficiently in cancer patients suspected of DVT. Direct referral for compression ultrasonography appears to be the preferred approach for diagnosis of suspected DVT in cancer patients.

\section{KEYWORDS}

clinical decision-making, decision support techniques, D-dimer, neoplasms, venous thrombosis

\section{1 | INTRODUCTION}

Accurate diagnosis of deep vein thrombosis (DVT) is challenging because individual symptoms and signs in isolation are of limited value. ${ }^{1}$ Moreover, patients with a missed or delayed DVT diagnosis are at risk of pulmonary embolism, as well as an increased risk of debilitating symptoms of postthrombotic syndrome. ${ }^{2}$ Consequently, physicians are likely to perform additional diagnostic testing in patients with symptoms or signs of DVT even when the possibility of DVT is low, resulting in only around $10 \%$ to $25 \%$ of patients who undergo imaging studies like compression ultrasound (CUS) being found to have DVT. ${ }^{2}$

To overcome these challenges, diagnostic decision rules have been developed to identify patients who can safely avoid imaging studies. ${ }^{3-5}$ We previously reported the findings of a large individual participant data (IPD) meta-analyses that used data from 13 diagnostic studies across the globe, ${ }^{4,6-17}$ and investigated ways to diagnose DVT in various subgroups of patients with suspected DVT. ${ }^{18}$ We found that the combination of a low probability of the Wells rule plus a negative D-dimer testing safely and efficiently excludes DVT in patients without cancer. ${ }^{18}$ However, this approach showed neither safety nor efficiency in suspected DVT patients with cancer.

In the current analysis, we therefore used this large scale IPD data set to explore reasons for this reduced diagnostic accuracy of the Wells rule. Next, with the aim to find a way to optimize the diagnostic pathway of suspected DVT in cancer patients, we developed a prediction model in patients with cancer who present with symptoms or signs of DVT.

\section{2 | METHODS}

\section{1 | Study selection and identification}

This was a meta-analysis using IPD from 13 diagnostic studies across the world, including patients with leg complaints suspected

\section{Essentials}

- Deep vein thrombosis (DVT) is highly prevalent $(40 \%)$ in suspected patients with cancer.

- Both the Wells-rule and D-dimer and a newly developed rule do not enable safe exclusion of DVT.

- Direct referral for compression ultrasonography may be preferred in most cancer patients.

of DVT by their treating physician. The process of study identification, selection, and construction of the IPD database was previously described. ${ }^{18}$ In short, the IPD set included the following items: age, sex, setting of care (primary/secondary/tertiary), all 10 items of the Wells rule (including history of DVT), the presence or absence of DVT based on the result of either of three reference standards (CUS, venography, or clinical follow-up), and the results of D-dimer testing (quantitative or qualitative). Ethical approval including written informed consent was obtained in each original study. No additional ethical approval was required for this meta-analysis.

\section{2 | Missing data}

Missing data were either partially missing (missing in only a subset of patients within each study) or systematically missing (completely missing in a particular study). ${ }^{19}$ To avoid bias caused by excluding patients with missing data, we first used a multivariable regression technique using all observed information to impute partially missing values within each individual study. ${ }^{20}$ Next, only for systematically missing results of $D$-dimer testing ( $n=2377,23.8 \%$ of the IPD; missing in five studies), ${ }^{7,8,11,12,15}$ we used a generalized linear mixed model for imputing these D-dimer results (dichotomized only), again using all the available clinical patient information both within and between studies. ${ }^{21}$ We did not impute quantitative $\mathrm{D}$-dimer results because they were only available for three of the included studies 
( $n=1930$, including only 136 patients with cancer, $19.3 \%$ of the IPD). ${ }^{10,14,16}$ To confirm the robustness of this approach, all analyses were repeated using only the patient data after imputation of the partially missing data. Twenty imputed datasets were created and subsequently analyzed and combined using Rubin's rules. ${ }^{22}$

\section{3 | Statistical analysis}

\subsection{1 | Comparison of DVT prevalence, Wells rule items, and D-dimer testing between patients with and without cancer}

To explore potential causes for the poorer performance of the Wells rule and D-dimer testing in cancer patients, we first compared the DVT prevalence between suspected patients with and without cancer. Next, the diagnostic performance of each Wells rule item was evaluated using (random effects) multilevel logistic regression modelling (patients nested within each study). ${ }^{23}$ This analysis yields odds ratios (OR) for the presence of DVTs that were visually compared between patients with and without cancer. For ORs, 95\% confidence intervals ( $\mathrm{Cl}$ ) and $95 \%$ prediction intervals (PI) were estimated. The PI estimates performance of each predictor when evaluated in new populations, taking heterogeneity across studies into account.

\subsection{2 | Diagnostic strategy}

To develop a new prediction model for diagnosis of DVT in suspected patients with cancer ("DVT-cancer rule"), we used multilevel logistic modelling (with a random effect for the intercept) that included age, sex, all original Wells rule items (including also history of DVT), and D-dimer test results (dichotomized as positive or negative using assay-specific cutoffs) as potential predictors. Age was evaluated as a continuous variable using restricted cubic splines to accommodate the possibility of a nonlinear relationship. ${ }^{24,25}$ Selection of predictors for the final model was done using backward elimination by mean squared error. Next, internal-external cross-validation (IECV) was applied. ${ }^{26}$ This approach yields a developed model in the total IPD set, whereas one study was iteratively excluded, in which it was then subsequently validated. It is an extended form of internal validation that can evaluate the generalizability of the developed model by taking all clusters in the IPD into account. ${ }^{26}$ Overall model performance was evaluated in terms of discrimination (c-statistic) and calibration (a calibration plot and observed-expected ratio). ${ }^{27}$

Next, we explored if this new DVT-cancer rule can safely and efficiently exclude DVT. Similar as done in previous diagnostic DVT studies performed in this field, we predefined that to be able to exclude DVT without imaging, the model had to be able to identify a substantial subset of patients with a predicted probability of DVT presence no higher than $2 \%{ }^{28,29}$ Finally, these analyses were repeated using 5\% and $10 \%$ instead of $2 \%$ as the predicted posttest probability threshold.

\subsection{3 | Sample size estimation}

This analysis used all eligible data from the 13 diagnostic studies. In derivation of the DVT-cancer rule, we had 13 potential predictors with age incorporated using restricted cubic splines with 5 knots (4 degrees of freedom), yielding a total of 16 candidate predictors. Therefore, according to a rule of at least 10 outcome events per variable, we needed (at least) 160 cancer patients with DVT to construct a reliable logistic regression model. ${ }^{30}$ The 13 studies included 317 cancer patients with DVT, corresponding to close to 20 outcome events for each candidate predictor.

All analyses were performed using SPSS (version 18.0, IBM) and $R$ version 3.6.0, in particular the Ime4 package ( $R$ foundation for Statistical Computing, www.R-project,org). ${ }^{31}$

\section{3 | RESULTS}

\section{1 | Study and patient characteristics}

Study characteristics are described in the Table S1. The proportion of patients in each study who had cancer varied from $3.7 \%$ to 18.3\% (median, 6.3\%; interquartile range [IQR] 5.1-10.6). In total, of 10002 patients with clinically suspected DVT, 834 patients had cancer (8.3\%). Additional patient characteristics are shown in Table 1.

\subsection{Comparison of DVT prevalence, the Wells rule items, and D-dimer testing between patients with and without cancer}

The prevalence of DVT in these patients with cancer varied from $18.2 \%$ to $57.1 \%$ (median, 37.5\%; IQR, 30.8-45.5), whereas it was from $4.2 \%$ to $37.8 \%$ (median, $15.1 \%$; IQR, $11.5-16.7$ ) in patients without cancer (Table S1). The prevalence of DVT was higher in patients with cancer than in patients without cancer in all clinical pretest probability categories (Table S2). Among 834 patients with cancer, 108 (12.9\%) had an unlikely clinical probability with the original Wells rule (1 point or less) combined with a negative $\mathrm{D}$-dimer assay. Among these 108 patients, the (pooled) observed prevalence of DVT was $3.0 \%(95 \% \mathrm{Cl}, 0.0$ 9.4). On the other hand, 64 (7.7\%) had a low clinical probability (0 points or less) with a negative D-dimer assay. Among these 64 patients, the (pooled) observed prevalence of DVT was $4.0 \%$ (95\% Cl, 0.7-12.5).

Patient characteristics and the prevalence of Well rule items in cancer patients with and without DVT is shown in the Table S3. In comparison of diagnostic performance of the Wells rule items and D-dimer testing, most of the items showed similar associations with the presence of DVT in patients with and without cancer (Table 2). However, two of the Wells rule items showed an inverse association for the presence of DVT in patients with and 


\begin{tabular}{|c|c|c|c|}
\hline & $\begin{array}{l}\text { Patients with } \\
\text { Cancer }\end{array}$ & $\begin{array}{l}\text { Patients without } \\
\text { Cancer }\end{array}$ & \\
\hline Variables & $n=834$ & $\mathrm{n}=9168$ & $P^{a}$ \\
\hline Age, year; mean (SD) & $65.9(13.4)$ & $58.6(17.5)$ & $<.001$ \\
\hline Primary care setting, n (\%) & $173(20.7)$ & $2941(32.1)$ & $<.001$ \\
\hline Male, n (\%) & $366(43.9)$ & $3481(38.0)$ & .001 \\
\hline $\begin{array}{l}\text { Paralysis, paresis, or recent } \\
\text { immobilization of leg with plaster, } \\
\mathrm{n}(\%)\end{array}$ & $44(5.3)$ & $569(6.2)$ & .319 \\
\hline $\begin{array}{l}\text { Recently bedridden }>3 \text { d or major } \\
\text { surgery }<4 \text { wk, } n(\%)\end{array}$ & $140(16.8)$ & $971(10.6)$ & $<.001$ \\
\hline $\begin{array}{l}\text { Localized tenderness of deep } \\
\text { venous system, n (\%) }\end{array}$ & $419(50.2)$ & $4679(51.0)$ & .686 \\
\hline Entire leg swollen, n (\%) & $340(40.8)$ & $2427(26.5)$ & $<.001$ \\
\hline Calf swelling $>3 \mathrm{~cm}, \mathrm{n}(\%)$ & $346(41.4)$ & $2670(29.1)$ & $<.001$ \\
\hline Pitting edema, n (\%) & $477(57.2)$ & $4307(47.0)$ & $<.001$ \\
\hline Collateral superficial veins, $\mathrm{n}(\%)$ & $132(15.8)$ & $1084(11.8)$ & .001 \\
\hline $\begin{array}{l}\text { Alternative diagnosis as likely as or } \\
\text { more likely than DVT, n (\%) }\end{array}$ & $321(38.5)$ & $4441(48.4)$ & $<.001$ \\
\hline History of DVT, n (\%) & $68(8.2)$ & $961(10.5)$ & .027 \\
\hline Score of the Wells rule, mean (SD) & $2.5(1.9)$ & $0.9(1.9)$ & $<.001$ \\
\hline Positive D-dimer test, n (\%) & $611(73.3)$ & $4861(53.0)$ & $<.001$ \\
\hline Presence of DVT, n (\%) & 317 (38.0) & 1547 (16.9) & $<.001$ \\
\hline
\end{tabular}

TABLE 1 Comparison of patient characteristics, the Wells rule items, the result of D-dimer test, and prevalence of DVT between patients with and without cancer

Abbreviations: DVT, deep vein thrombosis; SD, standard deviation.

${ }^{a}$ Comparison between patient with and without cancer.

TABLE 2 Comparison of diagnostic performance of the Wells rule items and D-dimer testing between patients with and without cancer

\begin{tabular}{|c|c|c|c|c|}
\hline \multirow[b]{2}{*}{ Variables } & \multicolumn{2}{|c|}{ Patients with Cancer } & \multicolumn{2}{|c|}{ Patients without Cancer } \\
\hline & $\begin{array}{l}\text { Odds ratio } \\
(95 \% \mathrm{Cl})\end{array}$ & $95 \% \mathrm{PI}$ & $\begin{array}{l}\text { Odds ratio } \\
\text { (95\% Cl) }\end{array}$ & $95 \% \mathrm{PI}$ \\
\hline $\begin{array}{l}\text { Paralysis, paresis, or recent immobilization of leg } \\
\text { with plaster }\end{array}$ & $0.85(0.44-1.65)$ & $0.40-1.82$ & $1.55(1.11-2.18)$ & $0.67-3.59$ \\
\hline Recently bedridden $>3 \mathrm{~d}$ or major surgery $<4 \mathrm{wk}$ & $1.52(1.03-2.23)$ & $0.87-2.63$ & $1.94(1.61-2.34)$ & $1.53-2.45$ \\
\hline Entire leg swollen & $1.82(1.09-3.03)$ & $0.37-9.04$ & $3.19(2.46-4.13)$ & $1.36-7.49$ \\
\hline Calf swelling $>3 \mathrm{~cm}$ & $3.49(2.45-4.98)$ & $1.69-7.23$ & $4.01(3.38-4.76)$ & $2.60-6.20$ \\
\hline Pitting edema & $1.67(1.12-2.47)$ & $0.58-4.76$ & $2.47(1.96-3.11)$ & $1.20-5.08$ \\
\hline Collateral superficial veins & $1.48(0.93-2.36)$ & $0.52-4.21$ & $1.91(1.58-2.30)$ & $1.45-2.50$ \\
\hline $\begin{array}{l}\text { Alternative diagnosis as likely as or more likely } \\
\text { than DVT }\end{array}$ & $0.20(0.11-0.36)$ & $0.04-1.01$ & $0.26(0.18-0.39)$ & $0.06-1.16$ \\
\hline
\end{tabular}

Abbreviation: $\mathrm{Cl}$, confidence interval; DVT, deep vein thrombosis; $\mathrm{PI}$, prediction interval.

${ }^{a}$ Only included in the modified version of Wells-rule.

without cancer: "paralysis, paresis, or recent immobilization of leg with plaster" (OR 0.85 vs 1.55) and "history of DVT" (OR, 0.83 vs 1.78). Although it was statistically significant in patients without cancer, it was no longer statistically significant in patients with cancer.

\subsection{The DVT-cancer rule for diagnosis of DVT in patients with cancer}

After the backward selection of candidate predictors, age, immobility (defined as paralysis, paresis, or recent immobilization 
TABLE 3 The formula of the DVTcancer rule for diagnosis of DVT in patients with cancer

\begin{tabular}{|llll|}
\hline Variables & Coefficient & $\begin{array}{l}\text { Standard Error of } \\
\text { Coefficient }\end{array}$ & $P^{\mathrm{a}}$ \\
\hline Intercept & $-2.11^{\mathrm{b}}$ & 1.24 & .09 \\
\hline Age 1 & -0.01 & 0.03 & .80 \\
\hline Age 2 & 0.05 & 0.09 & .61 \\
\hline Age 3 & -0.97 & 0.67 & .15 \\
\hline Age 4 & 3.21 & 1.56 & .04 \\
\hline Paralysis, paresis, or recent immobilization & -0.39 & 0.40 & .33 \\
of leg with plaster & & & $<.01$ \\
\hline Calf swelling $>$ 3 cm & 1.00 & 0.18 & $<.01$ \\
\hline $\begin{array}{l}\text { Alternative diagnosis as likely as or more } \\
\text { likely than DVT }\end{array}$ & -1.21 & 0.19 & $<.01$ \\
\hline Positive D-dimer test & & & 0.37 \\
\hline
\end{tabular}

Abbreviation: DVT, deep vein thrombosis.

${ }^{a}$ Wald test for each variable.

${ }^{\mathrm{b}}$ The random effect for the intercept was 0.23 .
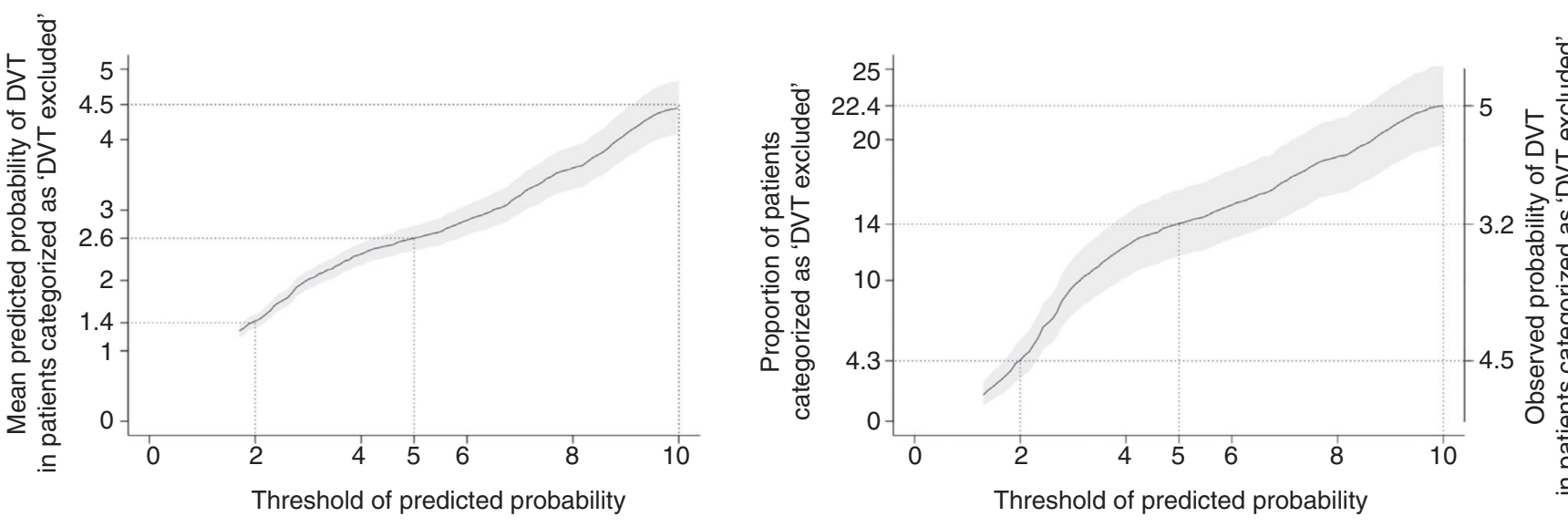

FIGURE 1 Diagnostic performance of the DVT-cancer rule across various thresholds of the predicted probability of DVT. Left panel: the mean predicted DVT probability (y-axis) for patients categorized as "DVT excluded" using various upper margins of the accepted posttest probability (x-axis). Right panel: the proportion of patients categorized as "DVT excluded" (left y-axis) and observed proportion of DVT in those patients (right $y$-axis) using various upper margins of the accepted posttest probability ( $x$-axis). Gray shaded areas surrounding the lines depict $95 \%$ confidence areas. DVT, deep vein thrombosis.

of leg with plaster), calf swelling $>3 \mathrm{~cm}$, alternative diagnosis as likely as or more possible than DVT, and positive D-dimer testing were included in the DVT-cancer rule (Table 3). A web calculator of the predicted probability of DVT based on this DVT-cancer rule is available online (https://dvt-ipd-cancer.shinyapps.io/App_ $\mathrm{dvt} /)^{32}$ In the whole IPD data set, the DVT-cancer rule showed a c-statistic of 0.81 (95\% Cl, 0.79-0.85) and good calibration (Figure $\mathrm{S} 1)$. In the IECV, the model showed a pooled c-statistic of 0.80 (95\% Cl, 0.75-0.83; 95\% PI, 0.68-0.88). The pooled observedexpected ratio was $1.03(95 \% \mathrm{Cl}, 0.87-1.21 ; 95 \% \mathrm{PI}, 0.67-1.59)$ (Figure S2).

Figure 1 shows the mean predicted probability of DVT (panel A) in patients categorized as "DVT excluded" based upon different thresholds of the upper margin of the accepted posttest DVT probability. Similarly, Figure 1 also shows the proportion of patients categorized as "DVT excluded" and the observed probability of DVT in those patients (panel B) at these various thresholds of the accepted posttest DVT probability. At the threshold of the (predicted) posttest probability of $2 \%$, the mean predicted and observed probability of those categorized as "DVT excluded" was $1.4 \%(95 \% \mathrm{Cl}, 1.3-1.5)$ and $4.5 \%(95 \%$ $\mathrm{Cl}, 0-11.6)$, respectively. Only $4.3 \%(95 \% \mathrm{Cl}, 3.0-5.7)$ of patients were categorized as "DVT excluded" using this threshold. At 5\% threshold, the mean predicted and observed probability of DVT in patients categorized as "DVT excluded" were $2.6 \%(95 \% \mathrm{Cl}$, 2.4-2.8) and 3.2\% (95\% Cl, 0.5-6.8), whereas at a $10 \%$ threshold, the mean predicted and observed probability of DVT in patients categorized as "DVT excluded" were $4.5 \%(95 \% \mathrm{Cl}, 4.1-4.8)$ and $5.0 \%(95 \% \mathrm{Cl}, 2.1-8.3)$, respectively. For the latter two thresholds, the proportion of patients categorized as "DVT excluded" were $14.0 \%(95 \% \mathrm{Cl}, 11.7-16.4)$ and $22.4 \%(95 \% \mathrm{Cl}, 19.6-25.3)$, respectively. 


\section{4 | DISCUSSION}

In this large diagnostic IPD meta-analysis of 13 studies, we observed a very high prevalence of thrombosis in cancer patients with suspected DVT (about 40\%). Consequently, DVT could be excluded in only $4 \%$ of patients with cancer using a cancer-specific diagnostic prediction model at the acceptable threshold of less than $2 \%$ posttest probability. Accordingly, direct referral to CUS without the measurement of D-dimer appears to be the preferred diagnostic workup for cancer patients with suspected DVT.

\section{1 | Clinical implications}

We believe that the findings of this analysis have several clinical implications. First, we demonstrated that the DVT prevalence in cancer patients with suspected DVT is high, both overall and in each clinical pretest probability category. This high pretest probability makes it almost impossible to rule out DVT without imaging in these patients at the commonly accepted safety threshold of not missing $2 \%$ or more DVT cases. Thus, for patients in whom this threshold of $2 \%$ is deemed clinically optimal, direct referral for CUS without measurement of D-dimer appears to be the preferable approach, both in terms of diagnostic efficiency and patient convenience. However, the optimum threshold for an acceptable predicted posttest DVT probability may be higher in patients with cancer, depending on clinical circumstances. As an extreme example, for patients with advanced cancer in palliative care settings, it has been reported that nonsymptomatic DVT was found on screening in one-third of patients and this was unrelated to overall survival. ${ }^{33}$ As such, for patients in advanced (palliative) cancer settings, the threshold of the predicted posttest probability for diagnosing DVT in symptomatic patients may be higher than in patients without cancer or in cancer patients with a good performance status or prognosis. For instance, in such clinical scenarios, a threshold of an accepted posttest probability of $5 \%$ or even $10 \%$ may still be acceptable. Our analyses demonstrate that, should this indeed be considered acceptable, the use of our developed model may enable an exclusion efficiency of up to around one in every five patients. Nevertheless, the clinical utility of such a diagnostic pathway first should be evaluated in a new prospective study using clinically relevant patient outcomes, such as overall survival, burden of symptoms, and quality of care.

\subsection{Strength and limitations}

The strength of our analysis is that we used IPD to create the largest dataset of prospectively collected cancer patients with suspected DVT published to date, thereby, to the best of our knowledge, providing the best assessment of the optimal diagnostic pathway for cancer patients with suspected DVT.

Several aspects of this work deserve specific attention. First, although we applied the IECV technique to quantify the performance range of the DVT-cancer rule in different populations, it should still be externally validated. Importantly, external validation is also needed as the studies included in the IPD were conducted between 2000 and 2009. In this era of rapid technological advances (eg, cancer treatment, ${ }^{34}$ D-dimer performance, ${ }^{35}$ imaging studies ${ }^{29}$ ), the model performance should be validated in contemporary datasets and adjusted if necessary. Second, we applied an advanced method to impute systematically missing values for D-dimer, including five studies that had no measurements of D-dimer. Although it has been established that ignoring partially (ie, nonsystematic) missing values may lead to biased results, ${ }^{36}$ the influence of ignoring systematically missing values is still uncertain. Therefore, we did perform sensitivity analyses after imputation of only partially missing data $(n=649)$. Very similar findings with this sensitivity analyses supported the robustness of the findings in the primary analyses (data not shown). Third, in 11 of the 13 included studies, categorization of patients as having DVT was based on imaging studies that were done at clinical presentation, supplemented by events that occurred during 3 months of follow-up in patients who either did not have imaging at presentation (eg, DVT was considered excluded by clinical assessment and D-dimer testing) or who had negative imaging for DVT. Given the high thrombotic risk in patients with cancer, it is possible that some DVT diagnosed during follow-up were new events rather than events that were already present when patients were first evaluated. Because only $4 \%$ of all DVT were diagnosed during follow-up, such misclassification is unlikely to have much impact on these analyses. Finally, we could not use some potentially useful variables (eg, site/staging/treatment of cancer, and medication including possible thromboprophylaxis) because this information was not available in the IPD. Furthermore, as quantitative D-dimer levels were only available for three of the studies $(n=136$ patients with 55 confirmed DVT cases [ie, 40.4\%]), we were unable to examine if including $\mathrm{D}$-dimer as a continuous measurement would improve the performance of the DVT-cancer rule. ${ }^{37,38}$ However, in those three studies in which quantitative D-dimer levels were available, median quantitative D-dimer levels for cancer patients were $1000 \mathrm{ng} / \mathrm{mL}$ (IQR, 541-1930) for those without DVT and $4104 \mathrm{ng} /$ $\mathrm{mL}$ (IQR, 2365-7770) for those with DVT, respectively. These high $\mathrm{D}$-dimer values in cancer patients indicate that $\mathrm{D}$-dimer testing, at least using the current thresholds (typically below $500 \mathrm{ng} / \mathrm{mL}$ or alternatively below $1000 \mathrm{ng} / \mathrm{mL}$ in patients with a very low pretest probability), likely is not very efficient to aid in the exclusion of DVT in cancer patients. Nevertheless, quantitative D-dimer testing may still provide predictive information, in particular if results are not dichotomized but rather evaluated as a continuous predictor over the full range of findings. Such an approach, which included both age and D-dimer as continuous measurements, was recently explored with the use of neural networks and showed good predictive performance, albeit not evaluated in the subset of only cancer patients. ${ }^{39}$

\section{5 | CONCLUSION}

In conclusion, the DVT prevalence in cancer patients with suspected DVT is high. Given this high pretest probability, it is 
challenging to exclude DVT in suspected patients with cancer using clinical assessment and qualitative D-dimer testing at the commonly accepted threshold of less than $2 \%$ posttest probability. Direct referral for compression ultrasonography therefore appears to be the preferred diagnostic approach in cancer patients with suspected DVT.

\section{CONFLICT OF INTEREST}

Dr. Takada is supported by the Uehara Memorial Foundation. Dr. Kearon is supported by the Jack Hirsh Professorship in Thromboembolism and is an investigator of the CanVECTOR Network and the Thrombosis and Atherosclerosis Research Institute, Canada. Dr. Geersing is supported by a Veni and Vidi grant from the Netherlands Organization of Health Research and Development. The remaining authors have disclosed no conflicts of interest.

\section{AUTHOR CONTRIBUTIONS}

Toshihiko Takada was involved in study design, data analysis, data interpretation, writing, and critical review and final approval of the report. Sander van Doorn was involved in study design, data collection, data analysis, data interpretation, and critical review and final approval of the report. Sameer Parpia, Kerstin de Wit, and Clive Kearon were involved in data interpretation and critical review and final approval of the report. David R. Anderson, Scott M. Stevens, Scott C. Woller, Arina J. ten Cate-Hoek, Johan L. Elf, Roderik A. Kraaijenhagen, Roger E.G. Schutgens, Phil S. Wells, and Karel G.M. Moons were involved in data collection, writing, and critical review and final approval of the report. Geert-Jan Geersing was involved in study design, data collection, data analysis, data interpretation, study coordination, writing, and critical review and final approval of the report.

\section{ORCID}

\section{Scott C. Woller iD https://orcid.org/0000-0002-2522-2705}

\section{REFERENCES}

1. Goodacre S, Sutton AJ, Sampson FC. Meta-analysis: the value of clinical assessment in the diagnosis of deep venous thrombosis. Ann Intern Med. 2005;143:129-139.

2. Wells PS, Owen C, Doucette S, Fergusson D, Tran H. Does this patient have deep vein thrombosis? JAMA. 2006;295:199-207.

3. Kahn SR, Joseph L, Abenhaim L, Leclerc JR. Clinical prediction of deep vein thrombosis in patients with leg symptoms. Thromb Haemost. 1999;81:353-357.

4. Oudega R, Moons KG, Hoes AW. Ruling out deep venous thrombosis in primary care. A simple diagnostic algorithm including D-dimer testing. Thromb Haemost. 2005;94:200-205.

5. Wells PS, Anderson DR, Bormanis J, et al. Value of assessment of pretest probability of deep-vein thrombosis in clinical management. Lancet. 1997;350:1795-1798.

6. Anderson DR, Kovacs MJ, Kovacs G, et al. Combined use of clinical assessment and d-dimer to improve the management of patients presenting to the emergency department with suspected deep vein thrombosis (the EDITED Study). J Thromb Haemost. 2003;1:645-651.

7. Anderson DR, Wells PS, Stiell I, et al. Management of patients with suspected deep vein thrombosis in the emergency department: combining use of a clinical diagnosis model with D-dimer testing. J Emerg Med. 2000;19:225-230.

8. Bates SM, Kearon C, Crowther M, et al. A diagnostic strategy involving a quantitative latex D-dimer assay reliably excludes deep venous thrombosis. Ann Intern Med. 2003;138:787-794.

9. Buller HR, Ten Cate-Hoek AJ, Hoes AW, et al. Safely ruling out deep venous thrombosis in primary care. Ann Intern Med. 2009;150:229-235.

10. Elf JL, Strandberg K, Nilsson C, Svensson PJ. Clinical probability assessment and $\mathrm{D}$-dimer determination in patients with suspected deep vein thrombosis, a prospective multicenter management study. Thromb Res. 2009;123:612-616.

11. Kearon C, Ginsberg JS, Douketis J, et al. Management of suspected deep venous thrombosis in outpatients by using clinical assessment and D-dimer testing. Ann Intern Med. 2001;135:108-111.

12. Kearon C, Ginsberg JS, Douketis J, et al. A randomized trial of diagnostic strategies after normal proximal vein ultrasonography for suspected deep venous thrombosis: D-dimer testing compared with repeated ultrasonography. Ann Intern Med. 2005;142:490-496.

13. Kraaijenhagen RA, Piovella F, Bernardi E, et al. Simplification of the diagnostic management of suspected deep vein thrombosis. Arch Intern Med. 2002;162:907-911.

14. Schutgens RE, Ackermark P, Haas FJ, et al. Combination of a normal D-dimer concentration and a non-high pretest clinical probability score is a safe strategy to exclude deep venous thrombosis. Circulation. 2003;107:593-597.

15. Stevens SM, Elliott CG, Chan KJ, Egger MJ, Ahmed KM. Withholding anticoagulation after a negative result on duplex ultrasonography for suspected symptomatic deep venous thrombosis. Ann Intern Med. 2004;140:985-991.

16. Toll DB, Oudega R, Bulten RJ, Hoes AW, Moons KG. Excluding deep vein thrombosis safely in primary care. J Fam Pract. 2006;55:613-618.

17. Wells PS, Anderson DR, Rodger M, et al. Evaluation of D-dimer in the diagnosis of suspected deep-vein thrombosis. N Engl J Med. 2003;349:1227-1235.

18. Geersing GJ, Zuithoff NP, Kearon C, et al. Exclusion of deep vein thrombosis using the Wells rule in clinically important subgroups: individual patient data meta-analysis. BMJ. 2014;348:g1340.

19. Resche-Rigon M, White IR. Multiple imputation by chained equations for systematically and sporadically missing multilevel data. Stat Methods Med Res. 2018;27:1634-1649.

20. Moons KG, Donders RA, Stijnen T, Harrell FE Jr. Using the outcome for imputation of missing predictor values was preferred. J Clin Epidemiol. 2006;59:1092-1101.

21. Jolani S, Debray TP, Koffijberg H, van Buuren S, Moons KG. Imputation of systematically missing predictors in an individual participant data meta-analysis: a generalized approach using MICE. Stat Med. 2015;34:1841-1863.

22. Marshall A, Altman DG, Holder RL, Royston P. Combining estimates of interest in prognostic modelling studies after multiple imputation: current practice and guidelines. BMC Med Res Methodol. 2009;9:57.

23. Debray TP, Moons KG, Abo-Zaid GM, Koffijberg H, Riley RD. Individual participant data meta-analysis for a binary outcome: onestage or two-stage? PLoS One. 2013;8:e60650.

24. Steyerberg EW. Prediction Model: A Practical Approach to Development, Validation, and Updating. New York, NY: Springer; 2019.

25. Harrell FE. Regression Modeling Strategies: With Applications to Linear Models, Logistic Regression, and Survival Analysis. New York, NY: Springer; 2015.

26. Debray TP, Moons KG, Ahmed I, Koffijberg H, Riley RD. A framework for developing, implementing, and evaluating clinical 
prediction models in an individual participant data meta-analysis. Stat Med. 2013;32:3158-3180.

27. Snell KI, Hua H, Debray TP, et al. Multivariate meta-analysis of individual participant data helped externally validate the performance and implementation of a prediction model. J Clin Epidemiol. 2016;69:40-50.

28. Bates SM, Jaeschke R, Stevens SM, et al. Diagnosis of DVT: antithrombotic therapy and prevention of thrombosis, 9th ed: American College of Chest Physicians Evidence-Based Clinical Practice Guidelines. Chest. 2012;141:e351S-e418S.

29. Dronkers CEA, Ende-Verhaar YM, Kyrle PA, et al. Disease prevalence dependent failure rate in diagnostic management studies on suspected deep vein thrombosis: communication from the SSC of the ISTH. J Thromb Haemost. 2017;15:2270-2273.

30. Moons KG, Altman DG, Reitsma JB, et al. Transparent Reporting of a multivariable prediction model for Individual Prognosis or Diagnosis (TRIPOD): explanation and elaboration. Ann Intern Med. 2015;162:1-73.

31. Core R, Team R.A language and environment for statistical computing. Available from: http://www.R-project.org [Accessed 23 April 2020].

32. The DVT-cancer rule for diagnosis of DVT in patients with cancer. Available from: https://dvt-ipd-cancer.shinyapps.io/App_dvt [Accessed 23 April 2020].

33. White C, Noble SIR, Watson M, et al. Prevalence, symptom burden, and natural history of deep vein thrombosis in people with advanced cancer in specialist palliative care units (HIDDen): a prospective longitudinal observational study. Lancet Haematol. 2019;6:e79-e88.

34. Pal SK, Miller MJ, Agarwal N, et al. Clinical cancer advances 2019 annual report on progress against cancer from the American Society of Clinical Oncology. J Clin Oncol. 2019;37:834-849.
35. Righini M, Perrier A, De Moerloose P, Bounameaux H. D-dimer for venous thromboembolism diagnosis: 20 years later. J Thromb Haemost. 2008;6:1059-1071.

36. Janssen KJ, Donders AR, Harrell FE Jr, et al. Missing covariate data in medical research: to impute is better than to ignore. J Clin Epidemiol. 2010;63:721-727.

37. Douma RA, le Gal G, Sohne M, et al. Potential of an age adjusted D-dimer cut-off value to improve the exclusion of pulmonary embolism in older patients: a retrospective analysis of three large cohorts. BMJ. 2010;340:c1475.

38. Schouten HJ, Geersing GJ, Koek HL, et al. Diagnostic accuracy of conventional or age adjusted D-dimer cut-off values in older patients with suspected venous thromboembolism: systematic review and meta-analysis. BMJ. 2013;346:f2492.

39. Willan J, Katz H, Keeling D. The use of artificial neural network analysis can improve the risk-stratification of patients presenting with suspected deep vein thrombosis. Br J Haematol. 2019;185:289-296.

\section{SUPPORTING INFORMATION}

Additional supporting information may be found online in the Supporting Information section.

How to cite this article: TakadaT, van Doorn S, Parpia S, et al. Diagnosing deep vein thrombosis in cancer patients with suspected symptoms: An individual participant data metaanalysis. J Thromb Haemost. 2020;18:2245-2252. https://doi. org/10.1111/jth.14900 